\title{
Psychological Impacts of Infertility Among Married Women Attending in a Tertiary Hospital, Dhaka
}

\author{
*J Alam ${ }^{1}$, M Rahman ${ }^{2}$, NE Afsana ${ }^{3}$
}

\begin{abstract}
Background: Infertility being a medical problem leads to various psychological problems. The stress of the non-fulfillment of a wish for a child has been associated with emotional sequel such as depression, anger, marital problems among infertile women. The study investigates the psychological impacts of infertility among married women suffering from infertility.

Material and Methods: This cross sectional descriptive study was carried out on 112 purposively selected infertile married women in outpatient department of Kormitola General Hospital, Dhaka. The Goldberg Depression questionnaires (GDQ) and Beck Anxiety Inventory (BAI) were administered to 112 married women with infertility. In addition to socio-demographic data, a structured questionnaire was used to collect obstetric information from the participants.

Results: The study showed $70(62.5 \%)$ infertile women showed different levels of depression (GDQ scale). Of these, $12(10.7 \%)$ had minor to moderate and $36(32.1 \%)$ had moderate to severe level of depression. According to BAI, $42(37.5 \%)$ responded suffered with anxiety disorders among them 14 $(12.5 \%)$ had moderate anxiety and $28(25.0 \%)$ potentially concerning levels of anxiety. Infertile women are worst victim of psychological morbidities with increasing age. Study showed that about $54 \%$ infertile women of more than 31years of age were suffering from minor to severe depression. Women who were infertile lower than 5 years, had lowest psychological disorders $\left(\chi^{2}=21.34, \mathrm{P}=.001\right.$ and $\left.\chi^{2}=8.5, \mathrm{P}=.01\right)$. About anxiety, women married for more than 11 years were the worst sufferer. Women neglected by their husband had a higher prevalence for psychiatric morbidity $\left(\chi^{2}=12.22, \mathrm{P}=.002\right)$. Women suffering from infertility scored significantly higher on all outcome measures of psychopathology. The results of the multiple regression analysis showed that the socio-demographic variables of the women with infertility contributed to the prediction of psychiatric morbidity (GDQ sacle), because of the effects of age, not having at least one child and lack of support from husband. Monthly family income, negligence of husband and violence by in laws family were important predicator for anxiety. Type of family, low level of education, unemployment were not found to be predictors of mental ill health.
\end{abstract}

Conclusion: Infertility is associated with high levels of psychiatric morbidity. Our findings reinforce the need of attention, counseling and others advance psychological interventions for positive impact on outcome during treatment of this group of women.

Key Words: Infertility, psychiatric morbidity, anxiety, depression, predictors

\section{Introduction}

Infertility is the inability to naturally conceive, carry infertility as not being able to get pregnant after at or deliver a healthy child. Most experts define least one year of trying. Infertility is a graver

\footnotetext{
$1 *$ Lieutenant Colonel Md Julfikkar Alam, Instructor Community Medicine, AFMI, Dhaka Cantonment

${ }^{2}$ Prof. Dr. Md. Mahfuzar Rahman, Professor and Head Dept. of Community Medicine, AKMMC

${ }^{3}$ Dr. Nister - E- Afsana, Medical Officer, Savar Thana Health Complex, Saver

*Corresponding Author
}

Date of submission: 18.06.2017, Date of acceptance: 15.09.2017 
concern affecting couples including loss of status within the family and community which may lead to physical, emotional and financial burden. Among $10 \%-15 \%$ of infertile couples of reproductive age all over the world, global data confirms that $40 \%$ of infertility are related with male, $40 \%$ are femalerelated and $20 \%$ are related to both or to unknown causes. In some communities the childbearing inability is almost always attributed only to "woman" and that women are often blamed for infertility even if the cause of infertility does not relate to them. ${ }^{1,2,3}$

Infertility remains a neglected issue in Bangladesh's reproductive health policy; instead, the emphasis has always been on the problem of overpopulation. Although no epidemiological study has been conducted in the national level on this issue in Bangladesh, a global review of infertility from the World Fertility Survey estimated infertility rates in South Asian countries stated $4 \%$ in Bangladesh. Another estimate in South Asia, on the basis of women at the end of their reproductive lives in the age group 45-49 years, suggests an infertility rate of approximately $15 \%$ in Bangladesh. There is evidence that potential causal factors of infertility are also widely present in Bangladesh. ${ }^{4}$

In recent years, the number of couples seeking treatment for infertility has dramatically increased. The stress of the non-fulfillment of a wish for a child has been associated with emotional squeal such as anger, depression, anxiety, marital problems and feelings of worthlessness among the parents. In general, among infertile couples, women show higher levels of distress than their male partners. Various research studies support the theory that distress is associated with lower pregnancy rates among women pursuing infertility treatment. Since psychological factors play an important role in the pathogenesis of infertility, exploration of this is also an important task to manage this devastating problem, which has cultural and social impact. This cross-sectional descriptive study is an attempt in dealing with the social and psychological consequences of infertility, regardless of their inadequacies in sorting out cause and effect. ${ }^{5}$

\section{Materials and methods}

This descriptive cross-sectional study of factors affecting the mental health of women suffering from infertility was conducted at the Obstetrics/Gynaecology outpatient department of Kormitola Hospital, Dhaka, Bangladesh. The teaching hospital provides tertiary level health care to population of northern portion of Dhaka city. Permission to carry out the study was given by concern Hospital Authority. Verbal informed consent was obtained from participants after the aims and objectives of the study had been explained to them. Participants were consecutively recruited at the time of their first presentation over a period of two months between March and April 2017. For this study, infertility was defined as primary if conception has never occurred in the subject, and secondary if conception failed to occur after a previous pregnancy irrespective of the pregnancy outcome and participants engaged in regular sexual intercourse without contraception for over one year. Subjects who received treatment for infertility before a previous pregnancy were excluded from the study. Also excluded were those with a past history of clinically diagnosed mental illness. The subjects were 124 infertile women $\geq 18$ years of age who attended the outpatient department for treatment of their infertility problems.

After obtaining consent from each patient, data were collected using Goldberg Depression questionnaires (GDQ) and Beck Anxiety Inventory (BAI). GDQ, an 18 item questionnaire, refers to how respondents have felt and behave during that situation. It was design by Dr. Ivan K. Golgberg a prominent New York psychiatrist as a quick assessment tool depressive disorder. It is a set of six self-report scales. Beck Anxiety Inventory (BAI) created by Aaron T. Beck and other colleagues, is a set of three self-report scales for the assessment of anxiety severity with scores of 21 and above indicating significant symptoms, scores of 22 - 35 indicate moderate anxiety and 36 and above are potentially concerning level of anxiety. Both of these sets had been validated for use in the primary care setting. The questionnaire was translated into Bengali language also. Respondents' data were analyzed by 
using the Statistical Package for Social Sciences 19.0 for Windows (SPSS Inc. Chicago, Ill.). A value of $\mathrm{p}<0.05$ was considered significant. 6,7

\section{Result}

Altogether one hundred and twenty four infertile married women were recruited into the study, but eight respondents' data were discarded during data cleaning process and who declined participation. The study sample was therefore made up of 112 infertile married women. Of the 112 infertile married women $86(62.5 \%)$ were diagnosed as suffering from primary infertility and $26(23.2 \%)$ as cases of secondary infertility. The mean duration of infertility of those women was $4.46 \pm 3.73$ years (Range $>1-18$ years).
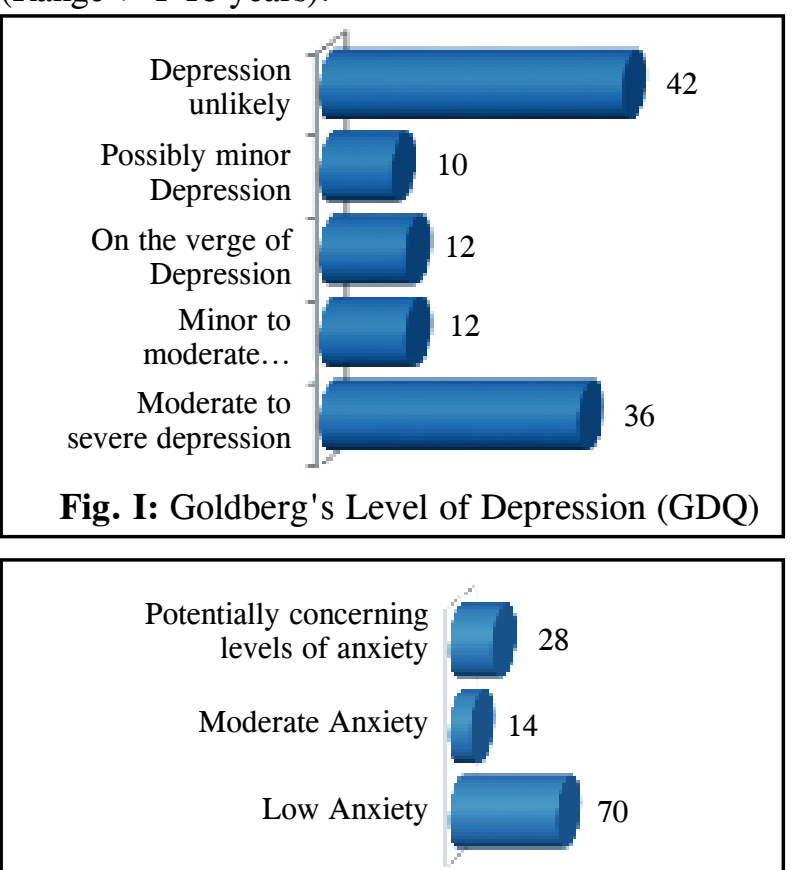

Fig. II: Beck Anxiety Inventory Level of Anxiety (BAI)

Figure I \& II. showed that, psychiatric outcomes of the infertile married women. As per GDQ record, out of 112 participants 42 has no depression. The remaining $70(62.5 \%)$ showed deferent levels of depression. Of these, $12(10.7 \%)$ had minor to moderate and $36(32.1 \%)$ had moderate to severe level of depression. Figure 2 shows that, 70 had no anxiety but remaining $42(37.5 \%)$ anxiety disorders which include moderate anxiety $14(12.5 \%)$ and 28 $(25.0 \%)$ potentially concerning levels of anxiety.
Table-I: Psychiatric outcome by Socio-demographic characteristics and other factors related to women with Infertility $(n=112)$

\begin{tabular}{|c|c|c|c|c|}
\hline \multirow[t]{2}{*}{ Variables } & \multicolumn{2}{|c|}{$\begin{array}{l}\text { Minor to severe } \\
\text { depression (\%) } \\
\text { (by GDQ ) }\end{array}$} & \multicolumn{2}{|c|}{$\begin{array}{l}\text { Moderate to Severe } \\
\text { anxiety (\%) } \\
\text { (by BAI) }\end{array}$} \\
\hline & Yes & No & Yes & No \\
\hline \multicolumn{5}{|l|}{ Age group } \\
\hline$<20-30$ years $(n=60)$ & $20(33.3)^{*}$ & $40(66.7)$ & $20(33.3)^{*}$ & $40(66.7)$ \\
\hline $31-40$ years $(n=30)$ & $18(60.0)$ & $12(20.0)$ & $10(33.3)$ & $20(66.7)$ \\
\hline$>41$ years $(n=22)$ & $10(45.5)$ & $12(20.0)$ & $12(54.5)$ & $10(45.5)$ \\
\hline \multicolumn{5}{|l|}{ Type of family } \\
\hline Nuclear $(n=49)$ & $18(36.7)$ & $31(63.2)$ & $17(34.7)$ & $32(65.3)$ \\
\hline Joint $(n=63)$ & $30(47.6)$ & $33(52.4)$ & $25(39.7)$ & $38(60.3)$ \\
\hline \multicolumn{5}{|l|}{ Occupational status } \\
\hline House wife $(\mathrm{n}=98)$ & $42(45.2)$ & $50(54.8)$ & $32(32.7)^{* *}$ & $60(67.3)$ \\
\hline Employed $(n=14)$ & $6(42.9)$ & $8(57.1)$ & $10(71.4)$ & $4(28.6)$ \\
\hline \multicolumn{5}{|l|}{ Level of Education } \\
\hline $\begin{array}{l}\text { Eight years or more ( } \\
=92)\end{array}$ & $36(39.1)$ & $56(60.9)$ & $36(39.1)$ & $56(60.9)$ \\
\hline $\begin{array}{l}\text { Seven years or less } \\
(n=20)\end{array}$ & $12(60.1)$ & $8(40.0)$ & $6(30.0)$ & $14(70.0)$ \\
\hline \multicolumn{5}{|l|}{ Duration of infertility } \\
\hline$<5$ years $(n=40)$ & $14(35.0) * * *$ & $26(65.0)$ & $10(25.0)^{* *}$ & \\
\hline $6-10$ years $(n=58)$ & $38(65.5)$ & $20(34.5)$ & $22(37.9)$ & $30(75.0)$ \\
\hline$>11$ years $(n=14)$ & $14(100.0)$ & $0(0.0)$ & $10((71.4)$ & $36(62.1)$ \\
\hline Type of infertility & $36(41.9)$ & & & $4(28.6)$ \\
\hline $\begin{array}{l}\text { Primary infertility } \\
(n=86)\end{array}$ & $36(41.9)$ & $50(58.1)$ & $40(46.5)$ & $46(53.5)$ \\
\hline $\begin{array}{l}\text { Secondary infertility } \\
(\mathrm{n}=26)\end{array}$ & $12(46.2)$ & $14(53.8)$ & $8(30.8)$ & $18(69.2)$ \\
\hline \multicolumn{5}{|c|}{ Negligence by husband ${ }_{25(39.1)^{*}}$} \\
\hline Yes $(n=64)$ & $23(47.9)$ & $39(60.9)$ & $21(32.8)^{* *}$ & $39(67.1)$ \\
\hline $\operatorname{No}(\mathrm{n}=48)$ & & $25(52.1)$ & $21(43.8)$ & $27(56.2)$ \\
\hline
\end{tabular}

Mean Age with $S D=28.5(5.5)$, mean duration of infertility $4.46 \pm 3.73$ years (range-more than 1 year to 18 years).

$* p<.05, * * p<.01, * * * p<.001$

In finding of relationship of socio-demographic and others factors with psychiatric outcome in the study group, Table I. summarizes the association between psychiatric outcome measures and the characteristics of the infertility subjects. Those who were between 20 and 30 years of age had the lowest prevalence for depressive disorders $\left(\chi^{2}=05.07, \mathrm{P}=.05\right)$ and there was trend towards their being less victim of anxiety disorders $\left(\chi^{2}=5.88, \mathrm{P}=.053\right)$. Type of family, educational status and a diagnosis of primary or secondary infertility were not 
significantly associated with the outcome measures. The lowest psychological disorders were seen in women who were infertile lower than 5 years, and differences were significant both the scales $\left(\chi^{2}=21.34, \mathrm{P}=.001\right.$ and $\left.\chi^{2}=8.5, \mathrm{P}=.01\right)$. About anxiety, the best scores were for women who were married for $>11$ years. Anxiety disorders among the house wife had the highest prevalence when compared with the employed (Fisher's exact $\mathrm{P}=.008$ ). Women neglected by their husband had a higher prevalence for psychiatric morbidity $\left(\chi^{2}=12.22, \mathrm{P}=.002\right)$.

Table-II: Regression coefficients, $\mathrm{T}$ and significance values for predictor variables for Psychological impact on women with infertility

\begin{tabular}{lccc}
\hline Variables and predators & Beta & $\mathbf{t}$ & $\mathbf{p}$ \\
\hline GDQ & & & \\
Age group & $0.31^{* *}$ & 2.75 & 0.007 \\
Type of family & -.04 & -.39 & -.69 \\
Level of Education & 0.07 & 0.66 & 0.51 \\
Employment status & -.12 & -1.28 & .20 \\
Has at least one child & $-.33^{* * *}$ & -3.32 & .001 \\
Monthly family income & .10 & -1.02 & .03 \\
Negligence of husband & $-.23 *$ & -2.20 & .03 \\
Violence by in laws family & -.04 & -.46 & .64 \\
BAI & & & \\
Age group & .14 & 1.28 & .20 \\
Type of family & .13 & 1.49 & .14 \\
Level of Education & -.12 & -1.29 & .20 \\
Employment of respondent & -.07 & -.73 & .47 \\
Has at least one child & -.24 & -2.45 & .02 \\
Monthly family income & $-.20^{*}$ & -2.40 & .04 \\
Negligence of husband & $-.30^{* *}$ & -2.87 & .005 \\
Violence by in laws family & .12 & 1.23 & .22 \\
\hline
\end{tabular}

Note: $* p<.05, * * p<.01, * * * p<.001$

Standardized regression coefficients and significant test for each of the predictors are given in table II. The results of the multiple regression analysis showed that the socio-demographic variables of the women with infertility contributed to the prediction of the depressive disorders (GDQ) as there was significant relationship found with age, not having at least one child and negligence from husband. When the BDI scores were entered as the dependent variable, the regression equation was again highly significant for monthly family income, negligence of husband and violence by in laws family. The demographic variables of type of family, education and employment status did not contribute to anxiety and depression.

\section{Discussion}

Infertility has several effects on different dimensions of infertile couples specially women. The effect of infertility cause stress and can lead to anxiety, depression and other psychological and physical illnesses and also cause social abnormalities. Several studies have demonstrated that anxiety has a negative effect on fertility. Lapane et al indicated that depression plays a major role in the pathogenesis of infertility. Our study confirms that infertile women have high levels of anxiety and depression. ${ }^{8,9,10}$

Psychological problems of infertile patients are complex. According to Freeman et al, almost half of the infertile couples described infertility as the most upsetting experience of their lives, whereas in view with Nahar P. almost $80 \%$ of the infertile women described their infertility experience to be either stressful or very stressful. Various factors such as socio-demographic factors and other factors affect the psychology of infertile women. In our study, we found that the age, house wife suffered more for Anxiety disorders. Women neglected by their husband had a higher prevalence for psychiatric morbidity. With increasing duration of infertility, women were the worst victim of depressive as well as anxiety disorders. In that issue, our result confirms results of Abedinia et al that found statistical significant relationship between duration of infertility and depression and anxiety disorders. ${ }^{4,11,12,13}$

The predictors of poor mental health outcomes were age, not having at least one child, lack of a supporting relationship with spouse, violence by in laws family. The association between lack of husband's support and poor mental health in this study finding also support the findings of Matsubayashi et al. who observed that anxiety and depression in childless Japanese women were significantly associated with lack of husband's support and feeling stress. It is noteworthy that the 
stress women often experience as a result of infertility may influence their perception of their marriage and may undermine their ability to get the very support they needed. Not having at least one child was significantly associated with psychiatric morbidity in the participants. The intrusive nature of in-laws in family constitute potent sources of psychological morbidity for these women even though lack of support from in-laws did not predict any of the outcome in this study. Our findings that infertility is associated with high levels of psychological morbidity is in agreement with previous studies (Sami and Ali 2006, Monga et al 2004, King 2003). ${ }^{1,14,15}$

The finding that more than half of consecutive women attending a clinic for infertility treatment suffered from anxiety and depression has implications for the psychological care of infertile women, and wider social policies. Our findings reinforce the need for gynaecologists and healthcare professionals to look for psychosocial distress in women undergoing fertility treatment. The quality of life of women with fertility problems could be further improved if professionally supervised psychological interventions consider as an integral part in the management of female infertility.

\section{Conclusion}

Infertility is the worst life crisis. For many women, the effects of this crisis can be equated, to a certain extent, with those of a serious illness. In recent years, the number of couples seeking treatment for infertility has dramatically increased due to factors such as development of newer and more successful techniques for infertility treatment, and increasing awareness of available services. This increasing participation of infertility treatment has raised awareness and inspired investigation into the psychological ramifications of infertility as these psychiatric disorders were undiagnosed and untreated. Therefore, consideration has to be given to the association between psychiatric illness and infertility. Researchers have also looked into the psychological impact of infertility and of the prolonged exposure to intrusive infertility on mood and well-being.

\section{Acknowledgement}

We are grateful to director and all the staffs of Gynae and Obstetrics Outpatient department of Kormitola general Hospital, Dhaka for their invaluable help in distributing the questionnaires.

\section{Conflict of interest: None}

\section{References}

1. Monga M, Alexandrescu B, Katz SE. Impact of infertility on quality of life, marital adjustment, and sexual function. Urology J 2004; 63:126-130.

2. Van BF, Gerrits T. Quality of infertility care in poorresource areas and the introduction of new reproductive technologies. HR J 2001; 16: 215-219.

3. Berek JS. Berek \& Novak's Gynecology.14th ed. Lippincott Williams and Wilkins: Philadelphia; 2007.

4. Nahar P. Invisible women in Bangladesh: Stakeholders' views on infertility Services. ObGyn J, 2012; 4 (3): 149-156.

5. Deka PK, Sarma S. Psychological aspects of infertility. BJMP 2010; 3(3): 336.

6. Goldberg D, Hiller VF. Goldberg Depression questionnaires PM J 2006; 9:139-145.

7. Leyfe OT, Ruberg JL, Woodruff JB. Examination of the utility of the Beck Anxiety Inventory and its factors as a screener for anxiety disorders. Anxiety disorders $\mathrm{J}$ 2006; 20 (4): 444 -58.

8. Demyttenaere K, Nijs P, Steeno O. Anxiety and conception rates in donor insemination. Psychosom Obstet. Gynaecol J 2008; 8: 175-181.

9. Lapane LK, Zierler S, Lasatar TM. Is a history of depressive symptoms associated with an increased risk of infertility in women? Psychosom. Med J 2000; 57: 509-513.

10. Domar AD, Zuttermeister PC, Friedman R. Distress and conception in infertile women. AMWA J 2000; 54: 196-198.

11. Matsubayashi H, Hosaka T, Izumi $\mathrm{S}$ et al. Increased depression and anxiety in infertile Japanese women resulting from lack of husband's support and feelings of stress. GHP J 2004; 26: 398-404.

12. Freeman EW, Rickels K, Tausig J, et al. Emotional and psychosocial factors in follow-up of women after IVFET treatment, a pilot investigation. AOGS J 1999; 66: 517-521.

13. Abedinia N, Ramezan ZF, Aghsa MM. Relation between anxiety and depression with infertility duration. Payesh J 2002; 2: 253-258.

14. Sami N, Ali TS. Psychosocial consequences of secondary infertility in Karachi. PA J 2006; 56: 19-22.

15. King RB. Sub-fecundity and anxiety in a nationally representative sample. SSM J 2003; 56: 739-751. 